\title{
C Research Square \\ Experimental Analysis of Microhardness Changes of Subsurface Areas Affected by WEDM
}

\section{Katerina Mouralova ( $\nabla$ mouralova@fme.vutbr.cz )}

Brno University of Technology https://orcid.org/0000-0002-6025-2520

\section{Stefan Michna}

Jan Evangelista Purkyně University

\section{Radim Zahradnicek}

Brno University of Technology

Josef Bednar

Brno University of Technology

\section{Tomas Plichta}

Institute of Scientific Instruments of the CAS

Jiri Fries

Technical University of Ostrava

\section{Research Article}

Keywords: WEDM, electrical discharge machining, microhardness, machining parameters, subsurface layer.

Posted Date: April 28th, 2021

DOI: https://doi.org/10.21203/rs.3.rs-437613/v1

License: (c) (i) This work is licensed under a Creative Commons Attribution 4.0 International License. Read Full License

Version of Record: A version of this preprint was published at Proceedings of the Institution of Mechanical Engineers, Part E: Journal of Process Mechanical Engineering on February 10th, 2022. See the published version at https://doi.org/10.1177/09544089221078383. 


\section{Abstract}

The influence of the surface area by the impact of high temperatures after wire electric discharge machining (WEDM) is a known fact. However, the affected parameters also include a change in microhardness. In order to further investigate this statement, 5 different metallic and non-metallic materials were selected, from which three samples were always made with different settings of machine parameters (gap voltage, pulse on and off time, wire feed and discharge current). This examined not only the effect of the machining itself on the material but also whether the change in the microhardness of the material is affected by the setting of the machine parameters. In order to measure the microhardness of the subsurface layer, a metallographic preparation was made from each sample, which enabled accurate measurements always in the same area. Subsequent evaluation revealed that the microhardness may not be affected at all and everything depends only on the type of material being machined. The changes in microhardness affected by setting machine parameters are negligible.

\section{Introduction}

Wire electric discharge machining (WEDM) is a widely used unconventional machining technology that uses the thermoelectric principle to cut material. Between the two electrodes, which represent the material being machined and the wire (tool), periodically repetitive electrical pulses take place in the presence of a dielectric fluid, which systematically erode and evaporate the material. The machining takes place without the impact of conventional cutting forces, so it is possible to machine even very soft materials or thin-walled components [1-3]. With WEDM, all at least minimally electrically conductive materials can be machined, regardless of their mechanical or physical properties. For this reason, the technology is suitable for machining classically difficult to machine materials or materials that have already been heat treated. WEDM is an indispensable technological operation in many industries, such as the aerospace, automotive, food, military, medical and sports industries [4, 5].

Straka [6] in their paper focused on the direct influence of microhardened surface layer on the final surface quality of the machined tool steel EN X210Cr12. The hardness measurements on metallographic samples in heat affected zone were carried out using the Vickers Hardness Tester, however, for the hardness measurements of the basic material the Vickers microhardness test could not be applied due to the high values of the hardness of the evaluated samples. During the experiments, it was proved that the machining method has a minimal influence on the microhardness variations in the surface layer. But contrarily, there was a significant influence observed in the white layer zone, where a substantial growth of the microhardness and its subsequent drop was detected. Newton [7] focused on the hardness testing in their experiments in order to measure the hardness of the recast layer during the machining process. Within the experimental testing, the bulk hardness was indicated, with an increasing linear trend on each sample. This might suggest that the WEDM process softens the machined surface below the hardness of the bulk material. While studying the hardness of the recast layer, it was determined that the hardness values are lower than those of the bulk material. This proves the fact, that the decrease in recast layer hardness due to the WEDM process could be caused by the metallurgical changes uncovered in the 
EPMA. Moreover, this decrease might be also caused by the electrolysis happening in the de-ionized water dielectric, or also by residual stress and the dramatic rates of heating and cooling of the recast layer. Zakaria [8], while studying the effect of the WEDM cutting parameters, also focused on the hardness of the hybrid metal material. They tried to develop the optimization of machining parameters to obtain high surface quality and maximum hardness. It was found out that the significant factors for surface hardness are pulse on and off time and peak current. The highest level of hardness was obtained with the lowest level of pulse off time, and the lowest hardness - using the highest level of pulse off time. It was also proved that the decreasing of the surface hardness takes place due to the electrolytic erosion during the WEDM process.Li [9] studied the WEDM characteristics of Inconel 718 and focused on the white layers by trim cut and their microhardness. The measurements of the microhardness were taken at different discharge energy, corresponding to the main cut and three trim cuts. During the experiments, it was found that the white layer has a significantly reduced hardness compared to the bulk material, and this dramatic reduction in hardness suggests that significant thermal degradation occurs on EDMed surfaces regardless of discharge energy. However, the white layer of the EDMed carbon steel has higher hardness than the bulk material, which is caused by the rich $\mathrm{C}$ element, whereas the low $\mathrm{C}$ content of IN 718 would not make the white layer hard after quenching in the dielectric.Lin [10] studied the hardness of WEDM surface of Fe-30Mn-6Si and Fe-30MN-6Si-5Cr shape memory alloys in their paper, which was measured by a microvickers tester. The average hardness value was calculated from at least five test readings for each sample. It was concluded, that the effect of hardness arises from the formation of the $\mathrm{Cu}_{0.83} \mathrm{Si}_{0.17}$ compound, $\eta^{\prime}-(\mathrm{Cu}, \mathrm{Si})$ and $(\mathrm{Fe}, \mathrm{Cr})$ solid solutions in the recast layer. It was also proved, that the hardness of the matrix is not affected by the WEDM process. Klocke [11] in their studies about the structure and composition of the white layer in the WEDM process focused also on the microhardness testing according to the ISO-standard 4516 requirements. In order to be able to quantify the deviation in hardness and modulus of elasticity a sample with the same geometry but without the white layer, using grinding and polishing during the machining process. The experiments revealed that the alloyed molybdenum and copper increase the hardness of the steel. Moreover, all the presented chemical alterations of the white layer increase the hardness of the material, which could be further enhanced through the possible deposition of carbon from the dielectric. As the last step of the experiments, the local hardness in the white layer and in the area below this layer was quantified. It was found, that the hardness of the recast layer was significantly increased, and it was nearly doubled in the white layer compared to the parent material. Aspinwall [12] researched the workpiece surface roughness and integrity after WEDM and focused in the experiments on the microhardness variation and depth profile data as well. The experiments showed that there was no significant change in workpiece microhardness variation with cracking confined to the recast layer. Sharma [13] while evaluating the WEDM performance characteristics of Inconel 706, studied the microhardness of the cross-section of WEDMed surface employing the micro Vickers hardness tester, and it was measured at $10 \mathrm{kgf} \mathrm{load} \mathrm{with} \mathrm{the} \mathrm{dwell} \mathrm{time} \mathrm{of}$ $10 \mathrm{sec}$. the low and high setting of servo voltage and pulse on time were also employed for the measurements. According to the experiments, the subsurface microhardness was decreased due to quenching of dielectric fluid and due to multiple thermal loading during the WEDM process. The surface 
was also softened with the help of low carbon content of Inconel 706. According to the EDAX analysis of the recast surface, the presence of $\mathrm{Cu}$ and $\mathrm{Zn}$ caused the lowered hardness of the recast region.

Wire electric discharge machiningis a process with many input factors influencing the machining efficiency and the resulting quality of the machined surface, including its subsurface layer. Given that even in the current state of knowledge, the process of influencing a workpiece made of different materials is not fully explored, it is necessary to further expand the areas of research. For this reason, this study was performed, which comprehensively assesses the degree of influence of the subsurface layer for individual materials in the form of changes in its microhardness. This is linked to very extensive research of the behaviour of individual materials after WEDM, where subsurface defects of several different materialsaffecting the life of the part were studied [14], the machinability of Hadfield steel [15], Inconel [16], Creusabro steel [17] or aluminium alloy 7475-T7351 [18] were studied. The knowledge and possible prediction of the behaviour of individual materials after WEDM is key knowledge for machining parts with the highest possible surface quality without the occurrence of defects. This study is completely new in its scope, as no similar study has examined several materials simultaneously under the same conditions. If we have knowledge about the degree of change of microhardness of the subsurface layer of the material, it will be possible to better predict the life of the part.

\section{Experimental Setup And Material \\ 2.1. Experimental material}

Samples for the experiment were made of nickel superalloys B1914 and Nimonic 263, Hadfield steel, Creusabro 4800 and Hardox 400 . The properties of all these materials, including microstructures, were summarized in Table 1. Material B1914 was cast and delivered by PBS VelkáBíteš a.s. A 15 mm thick semi-product was used for all samples.

\subsection{WEDM machine setup}

A wire electric discharge machineof type EU64 from the company MAKINO was used for machining. The machine was equipped with CNC control in 5 axes and deionized water was used as a dielectric liquid. The wire electrode marked PENTA CUT E had a diameter of $0.25 \mathrm{~mm}$ and was made of $60 \% \mathrm{Cu}$ and $40 \%$ $\mathrm{Zn}$. To monitor the influence of individual input factors on the resulting microhardness of the subsurface layer, in our case the parameters of machine settings (gap voltage, pulse on and off time, wire feed and discharge current) different settings according to Table 2 were usedto produce three samples of each material. Extensive previous research has been conducted to specify these individual settings [19].

\subsection{Experimental methods}


Metallographic cuts of cross sections were prepared for the analysis of subsurface microstructural changes. These preparations were prepared by common techniques - wet grinding and diamond paste polishing using the automatic preparation system TEGRAMIN 30 from Struers. The final mechanicalchemical polishing was performed by vibro-polishing. After etching (Hadfield steel, Creusabro and Hardox were etched with Nital, Nimonic and B1914 were etched withkalling 2), the structure of the material was observed and documented by electron and light microscopy on an inverted light microscope (LM) Axio Observer Z1m from ZEISS and on a scanning electron microscope (SEM) of Lyra3typefrom TESCAN. A TI 950 triboindenter from HYSITRON with a Berkovictype tip with a diameter of $50 \mathrm{~nm}$ was used to measure the microhardness of the subsurface layer. The load curve followed a standard trapezoidal function with a total force of $8 \mathrm{mN}$ during the analysis. The electron backscatter diffraction (EBSD) analysis was performed on a Mira 3 microscope from TESCAN equipped with an EBSD analyser from OXFORD.

During the measurement, the change of microhardness according to the ASTM E384 methodology [20] depending on the distance from the machined surface was investigated using the WEDM technology. The maximum load of the indenter during the measurement reached $8000 \mu \mathrm{N}$, while its basic microhardness was measured in the middle of each sample. To determine the change both in the vicinity of the recast layer and in the base material, a total of 45 indentation measurements were performed on each sample, arranged in a $3 \times 15$ matrix with a distance of $3 \mu \mathrm{m}$ between the indents. In order to ensure the protection of the indentation tip, the beginning of the nut was always situated $3 \mu \mathrm{m}$ from the resin in which each sample was cast. An example of samples made of Creusabro 4800, a metallographic specimen, and a cross section with indents is shown in Fig. 1. The individual vertical rows of indents are hereinafter referred to as Line1, Line2 and Line 3 and the horizontal ones are numbered 1 to 15 .

\section{Results And Discussion}

\subsection{EBSD analysis}

Due to the thermal stress of the upper layer of the machined material due to the effects of the wire electric discharge machining and rapid cooling, some materials recrystallize and change the overall orientation of the grains. This phenomenon has been investigated previously by EBSD in studies such as Klocke [22], Salvati [23] or Liu [24]. The investigation of this process was performed on a Mira 3 microscope equipped with an EBSD analyser. A total of 20 measurements were made, always measuring in the middle of the sample in the base and completely unaffected material and then on each of the individual samples in the recast layer with a part of the base and unaffected material. Due to the orientation, the resin was always shown to a small extent, so that it is clear that this is the correct area, i.e. the recast layer. The size and resolution of the measurements are always given in the description of the figure, because the individual materials examined had different grain sizes and therefore it was not desirable to use the same resolution for all of them. The evaluation of the data was performed by means of the final comparison within one material at a time. 
In the case of material B1914 from a comparison of the base material and the individual samples shown in Fig. 2 (a), it is evident that due to WEDM there was recrystallization in the investigated area and individual grain size was reduced. From the comparison of inverse pole figures (IPF) it is clear that in the recast layer there was an overall decrease of individual grain orientations up to orientation 001 . Since each polefigure describes the angular rotation of individual grains with respect to the scanning plane, it is possible to determine the change in the orientation of the grains. From this finding, it can be concluded that in the case of B1914, there was a preferential change to the 001 orientation due to machining in the recast layer area.

In the case of EBSD measurement with Nimonic material, which is shown in Fig. 2 (b), no significant change in grain size was observed in the recast layer compared to the base material. This finding indicates only a minimal effect of WEDM on the material. A comparison of individual IPFs shows that the setting of the machine parameters significantly affected the overall orientation of the grains not only among themselves but also in comparison with the basic material.

From a comparison of the EBSD data for the Hadfield steel material shown in Fig. 2 (c), it is clear that again the grain size in the recast layer area decreased due to the WEDM process. In addition, crystal orientations (green colour of grain in the middle of the study area) were observed, which were not identified by the Oxford device. Unfortunately, these grains have an unknown crystal structure. From the comparison of the IPF image of the base material of Hadfield steel with other samples, it is evident that in the base material a uniform distribution of individual crystal orientations prevailed compared to individual samples affected by the WEDM process. This finding shows that there were significant changes in crystal orientation due to WEDM, both between individual samples and with respect to the base material.

In the case of EBSD measurements for Creusabro material (Fig. 3 (a)), no significant change in the size and distribution of the individual grains was observed. From the IPF data for Creusabro, it is clear that there was no significant change in the orientation of individual grains due to WEDM in comparison of the basic material with individual samples measured near the recast layer. The only visible difference is the distribution of grains in the y-axis, where the uniform distribution of individual crystal orientations dominates for the base material. There are most differences in the $y$-axis between the individual samples.

From a comparison of the EBSD figures for Hardox material shown in Fig. 3 (b) for individual samples and base material, it can be seen that grains with a smaller size dominate in the heat-affected areathan in the base material area. Mutual differences in orientation between individual samples are minimal in the $x$ and $y$-axis. In the z-axis, however, the change is more significant. If we compare the grain orientation of the base material, the predominant proportion of grain orientation 101 in the $y$-axis for the BCC grid is clearly visible.

\subsection{Microhardness analysis}


Due to the significant temperature rise and rapid cooling during WEDM machining, some materials have a change in microhardness $\mathrm{H}$ in the heat affected zone. The nanoindentation method was used to determine this effect. The measurement was performed on a Hysitron TI 950 device, while the measurement methodology was described in detail in Chap. 2.3, including the representation of individual indents on the sample. In the following maps for microhardness and reduced elastic modulus Er, shown in Figs. 4 and 5, for clarity, the distance from the sample surface is given instead of the number of individual indents (1-15).

From the graphs shown in Fig. 4, it is evident that for 2 of the studied materials there was no significant change in mechanical properties due to WEDM. These were the B1914 and Hardox 400 materials. A more significant change occurred with the Nimonic material, where the microhardness increased with increasing distance from the surface, which is supported by the Kumar study [21]. There was also a more significant change in Hadfield steel and Creusabro 4800 steel, while in Creusabro steel the initial value of microhardness was approximately 2 times smaller than the value for the basic heat-unaffected material, in Hadfield steel, it was 3 times smaller. In his study, Straka also noted a change in the microhardness of the subsurface layer during machining of X210Cr12 steel [6].

In addition to microhardness, the effect of machining on the reduced modulus of elasticity was evaluated, which includes the effect of the elastic response of the tip with the modulus of elasticity of the measured material. The obtained values were plotted in the graphs shown in Fig. 5. The trend of individual changes was similar to the case of the microhardness measurement itself, with the only difference that the growth of values from the surface was more significant. In the case of Nimonic, the overall growth was over 50\%. For Creusabro steel the value increased 3 times and for Hadfield steel 4 times.

The dependence of the observed characteristics ( $\mathrm{H}$ and $\mathrm{Er}$ ) on the distance from the sample surface cannot be described by the classical regression model, because due to local inhomogeneities the scattering of the model residues is not homogeneous. It is, therefore, necessary to test the dependencies using the correlation coefficient. The assumption of the independence test using the Pearson correlation coefficient is that the data come from a two-dimensional normal distribution, which our data do not satisfy. Therefore, the Spearman correlation coefficient Rho was used, which does not have this assumption in the independence test, and moreover, it is not only a measure of linear dependence but is a measure of monotonic dependence in general. Table 3 shows the Spearman correlation coefficient Rho of the observed characteristics ( $\mathrm{H}$ and $\mathrm{Er}$ ) and the distance from the sample surface for individual materials. Next, the p-value of the independence test is given in parentheses, where the quantities are independent if the $p$-value is greater than the selected significance level $a$, which was standardly selected as $5 \%$. Because the Rho coefficient is always positive, there is always an increase in these characteristics with increasing distance from the sample surface. These increases in characteristics are statistically significant for Creusabro 4800, Hadfield steel and Nimonic 263 ( $p$-value < 0.05), for the other two materials (B1914 and Hardox 400) these increases are statistically insignificant. Figure 6 (a) shows the dependence of $\mathrm{H}$ and Fig. 6 (b) shows the dependence of Er on the distance from the sample surface, 
where statistically significant dependences are highlighted by a solid line and statistically insignificant dependencies by a dashed line. Of a particular note,there is Nimonic 263, where the dependencies may seem graphically insignificant, yet they are significant.

\section{Conclusions}

In order to detect changes in the microhardness of the subsurface areas affected by WEDM, an extensive analysis was performed involving 5 different metallic materials (B1914, Nimonic 263, Hadfield steel, Creusabro 4800 steel and Hardox 400), 3 samples were produced from each material using different machine settings, while the following conclusions have been reached:

on the basis of the EBSD analysis, it was found that the samples of B1914, Hadfield steel and Hardox 400 steel wererecrystallized and the size of the individual grains was reduced, while the samples of Nimonic 263 and Creusabro 4800 showed no visible change,

from the IPF comparison it is clear that in the case of samples from B1914 there was a preferential change to orientation 001 in the area of recast layer due to WEDM, in samples of theNimonic material the setting of machine parameters significantly affected the overall grain orientation not only between them but also in comparison with the base material,

for Hadfield steel samples there was a significant change in crystal orientation on the basis of IPF, both between individual samples and with respect to the basic material, for Creusabro samples on IPF there was no significant change in grain orientation due to WEDM and in Hardox steel the samples are minimal on the $x$-and $y$-axis, but the change on the $z$-axis is more significant,

the microhardness analysis revealed that the samples of B1914 and Hardox 400 did not show a significant change in mechanical properties due to WEDM,

the samples made of Nimonic increased microhardness with the increasing distance from the surface,

a more significant change in microhardness occurred in samples made of Hadfield steel and Creusabro 4800 steel, with the initial microhardness value for Creusabro steel being approximately 2 times smaller than the value for the base heat-unaffected material and 3 times smaller for Hadfield steel,

the reduced modulus of elasticity had a trend of individual changes similar to that in the case of the microhardness measurement itself, with the only difference that the growth of values from the surface was more significant,

based on the statistical evaluation, it can be said that the increases in microhardness and reduced modulus of elasticity are statistically significant for Creusabro 4800, Hadfield steel and Nimonic 263 (pvalue $<0.05$ ), for the other two materials (B1914 and Hardox 400) these increases are statistically insignificant. 
Based on the above-mentioned conclusions, it can be clearly stated that changes in the microhardness of the subsurface layer after WEDM are clearly influenced by the type of material being machined and may not occur at all. However, the changes in microhardness affected by the setting of the machine parameters are negligible.

\section{Declarations}

\section{Fundings:}

We acknowledge CzechNanoLab Research Infrastructure supported by MEYS CR (LM2018110).

Supported by the OP VVV Project Development of new nano and micro coatings on the surface of selected metallic materials - NANOTECH ITI II., Reg. No CZ.02.1.01/0.0/0.0/18_069/0010045.

This work was supported by the Brno University of Technology Specific Research Program, project no. FSI-S-17-4464.

\section{Conflict of Interest:}

Authors K. Mouralova, S. Michna, R. Zahradnicek, J. Bednar, T. Plichta, J. Fries declares that they have no conflict of interest.

\section{Availability of data and material: no}

Code availability: Not applicable

Ethics approval: Authors K. Mouralova, S. Michna, R. Zahradnicek, J. Bednar, T. Plichta, J. Fries agree with Ethics

Consent to participate: Authors K. Mouralova, S. Michna, R. Zahradnicek, J. Bednar, T. Plichta, J. Fries agree.

Authors' contributions: Katerina Mouralova: Conceptualization, Methodology, Data curation, WritingOriginal draft preparation, Writing- Reviewing and Editing, Supervision. Stefan Michna: Validation, Funding acquisition. Radim Zahradnicek: Methodology, Data curation. Josef Bednar: Visualization, Formal analysis. Tomas Plichta: Methodology, Data curation. Jiri Fries: Data curation, Funding acquisition.

\section{References}

1. Vates UK, Wire-EDM process parameters and optimization (2018) ISBN: 978-620-2-30578-5

2. Hashmi S, Comprehensive materials finishing (2016) ISBN: 978-0-12-803249-7

3. Ranjan R, Optimization of Wire Electrical Discharge Machining (2016) ISBN: 978-3-659-88968-4 
4. Tonday HR, Tigga AM, WIRE ELECTRICAL DISCHARGE MACHINING: Empirical Study and Optimization (2017) ISBN: 978-3-330-32464-0

5. Ho KH, Newman ST, Rahimifard S, Allen RD (2004) State of the art in wire electrical discharge machining (WEDM). Int J Mach Tools Manuf 44(12):1247-1259

6. Straka L', Čorný I, Pitel' J, Properties evaluation of thin microhardened surface layer of tool steel after wire EDM. Metals, 6(5) (2016) 95

7. Newton TR, Melkote SN, Watkins TR, Trejo RM, Reister L (2009) Investigation of the effect of process parameters on the formation and characteristics of recast layer in wire-EDM of Inconel 718. Materials Science Engineering: A 513:208-215

8. Zakaria K, Ismail Z, Redzuan N, Dalgarno KW (2015) Effect of wire EDM cutting parameters for evaluating of Additive Manufacturing Hybrid Metal Material. Procedia Manufacturing 2:532-537

9. Li L, Guo YB, Wei XT, Li W (2013) Surface integrity characteristics in wire-EDM of Inconel 718 at different discharge energy. Procedia CirP 6:220-225

10. Lin HC, Lin KM, Chen YS, Chu CL (2005) The wire electro-discharge machining characteristics of Fe$30 \mathrm{Mn}-6 \mathrm{Si}$ and Fe-30Mn-6Si-5Cr shape memory alloys. J Mater Process Technol 161(3):435-439

11. Klocke F, Hensgen L, Klink A, Ehle L, Schwedt A (2016) Structure and composition of the white layer in the wire-EDM process. Procedia CIRP 42:673-678

12. Aspinwall DK, Soo SL, Berrisford AE, Walder G (2008) Workpiece surface roughness and integrity after WEDM of Ti-6Al-4V and Inconel 718 using minimum damage generator technology. CIRP Ann Manuf Technol 57(1):187-190

13. Sharma P, Chakradhar D, Narendranath S (2015) Evaluation of WEDM performance characteristics of Inconel 706 for turbine disk application. Materials Design 88:558-566

14. Mouralova K, Prokes T, Benes L (2019) Surface and subsurface layers defects analysis after WEDM affecting the subsequent lifetime of produced components. Arabian Journal for Science Engineering 44(9):7723-7735

15. Mouralova K, Benes L, Bednar J, Zahradnicek R, Prokes T, Matousek R, Fiserova Z, Otoupalik J (2019) Using a DoE for a comprehensive analysis of the surface quality and cutting speed in WED-machined hadfield steel. J Mech Sci Technol 33(5):2371-2386

16. Mouralova K, Benes L, Zahradnicek R, Bednar J, Hrabec P, Prokes T, Hrdy R (2019) Analysis of cut orientation through half-finished product using WEDM. Mater Manuf Processes 34(1):70-82

17. Mouralova K, Prokes T, Benes L, Sliwkova P, Analysis of subsurface defects occurrence in abrasion resistant Creusabro steel after WEDM including the study of morphology and surface topography. Machining Science and Technology(2019) 1-17

18. Mouralova K, Benes L, Zahradnicek R, Bednar J, Hrabec P, Prokes T, Matousek R, Fiala Z. Quality of surface and subsurface layers after WEDM aluminum alloy 7475-T7351 including analysis of TEM lamella. The International Journal of Advanced Manufacturing Technology, (2018) 1-18 
19. Mouralova K, Moderní technologie drátového elektroerozivního řezání kovových slitin. Thesis. Brno: CERM (2015) ISBN 80-214-2131-2

20. ASTM E384-17 (2017) Standard Test Method for Microindentation Hardness of Materials. ASTM International, West Conshohocken.

21. Kumar V, Jangra KK, Kumar V, Sharma N (2017) WEDM of nickel based aerospace alloy: optimization of process parameters and modelling. Int J Interact Des Manuf 11(4):917-929

22. Klocke F, Hensgen L, Klink A, Mayer J, Schwedt A (2014) EBSD-analysis of flexure hinges surface integrity evolution via wire-EDM main and trim cut technologies. Procedia CIRP 13:237-242

23. Salvati E, Korsunsky AM (2020) Micro-scale measurement \& FEM modelling of residual stresses in AA6082-T6 Al alloy generated by wire EDM cutting. J Mater Process Technol 275:116373

24. Liu JF, Li C, Fang XY, Jordon JB, Guo YB (2018) Effect of wire-EDM on fatigue of nitinol shape memory alloy. Mater Manuf Processes 33(16):1809-1814

\section{Tables}

Due to technical limitations, table 1-3 is only available as a download in the Supplemental Files section.

\section{Figures}

(a)

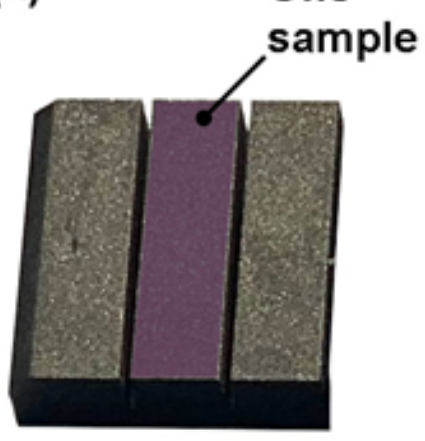

$5 \mathrm{~mm}$ (b)

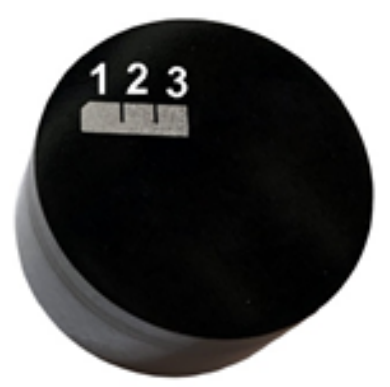

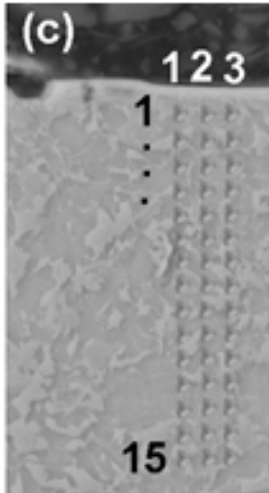

15

$5 \mu \mathrm{m}$

\section{Figure 1}

Example of samples from Creusabro 4800 material (a) manufactured samples, (b) metallographic preparation with samples, (c) microstructure in cross section showing individual indents (SEM). 

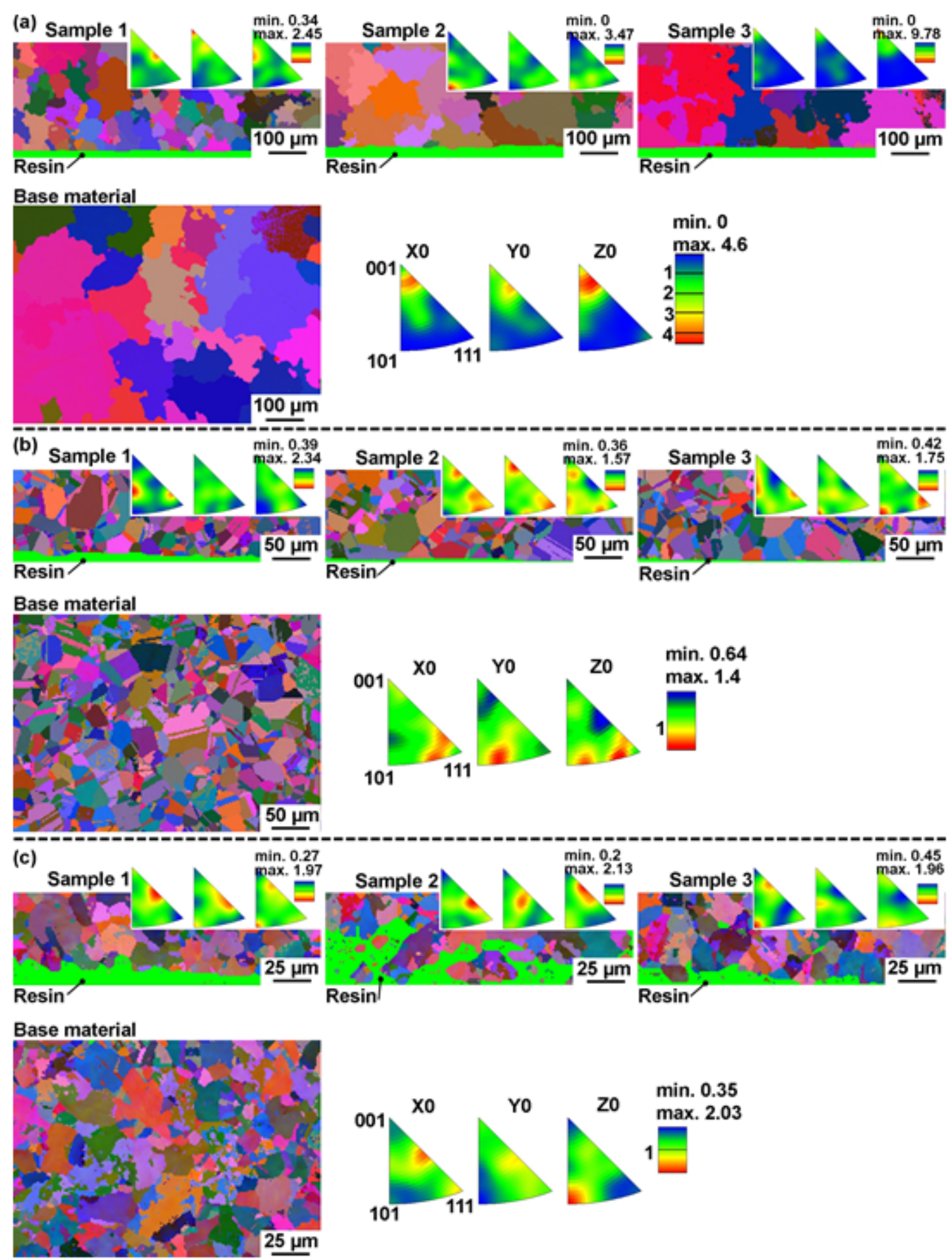

Figure 2

EBSD measurements and inverse pole figures for base material and Samples 1, 2 and 3 of individual materials (a) B1914 (crystal category: Ni-superalloy), (b) Nimonic 263 (crystal category: Ni-superalloy), (c) Hadfield steel (crystal category: Iron fcc: m3m). 

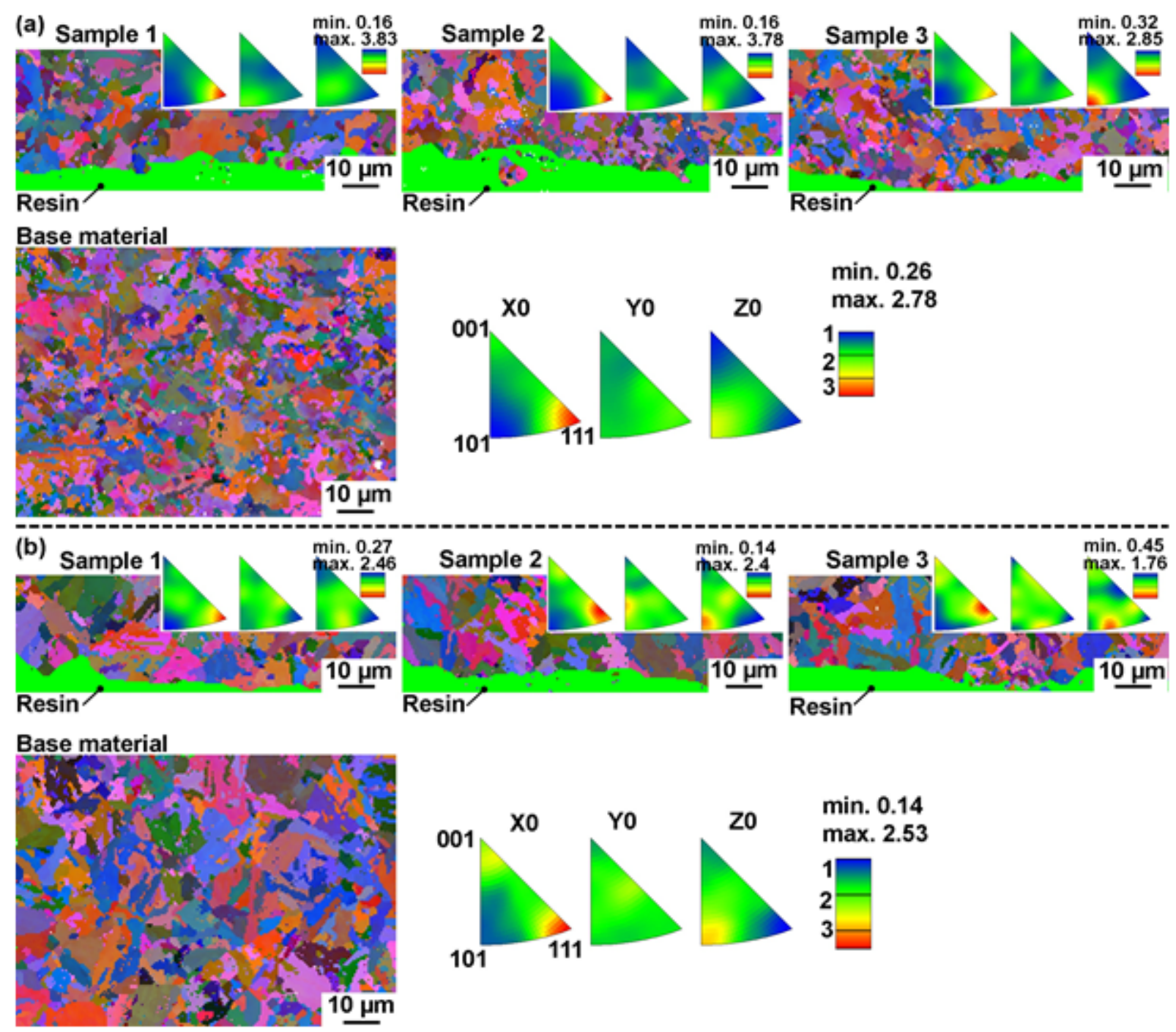

Figure 3

EBSD measurements and inverse pole figures for the base material and Samples 1, 2 and 3 of individual materials (a) Creusabro 4800 (crystal category: Fe-BCC: m3m), (b) Hardox 400 (crystal category: Fe-BCC: $\mathrm{m} 3 \mathrm{~m})$. 

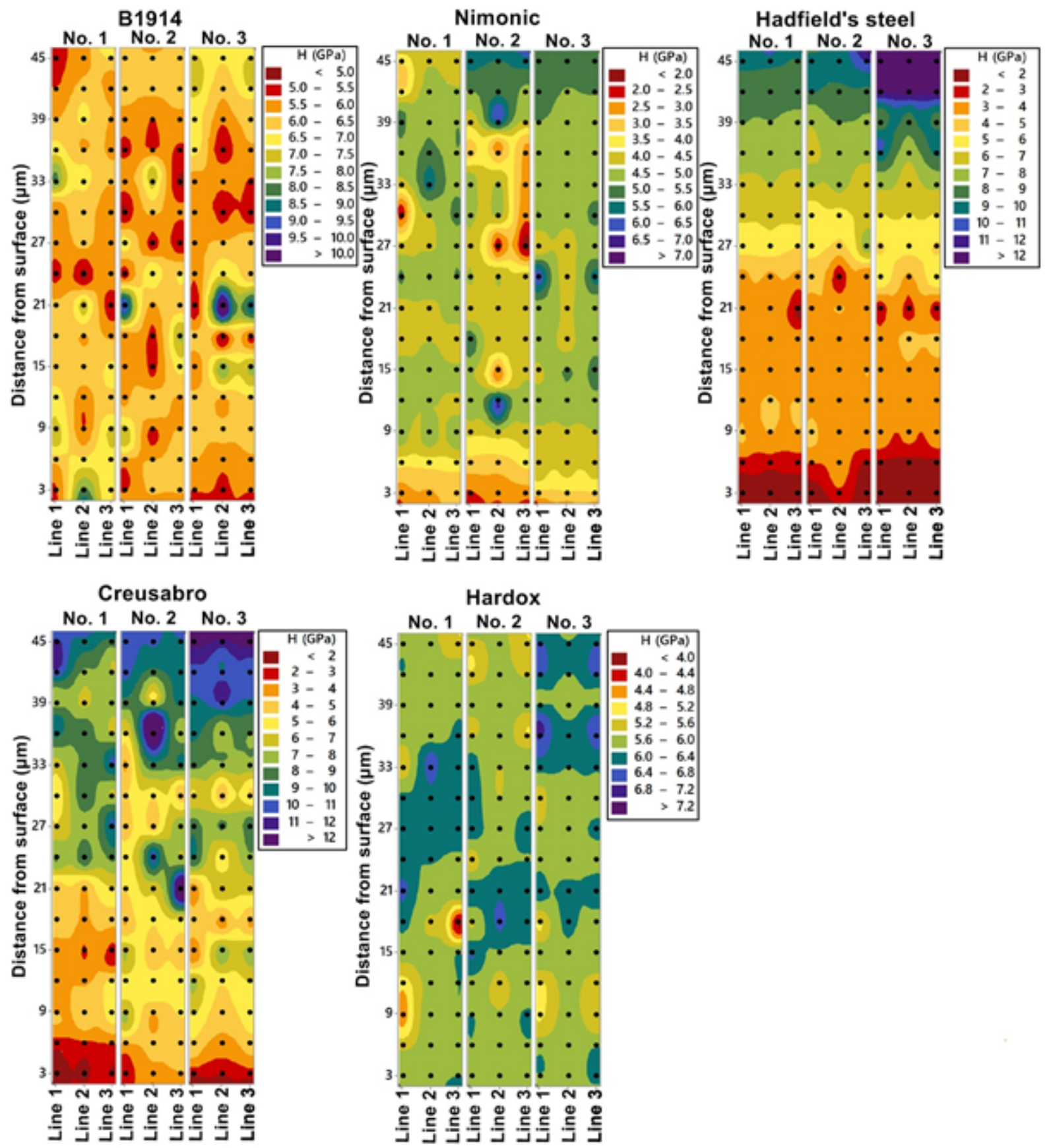

Figure 4

Microhardness maps for individual materials and Samples made of them 1,2 and 3. 

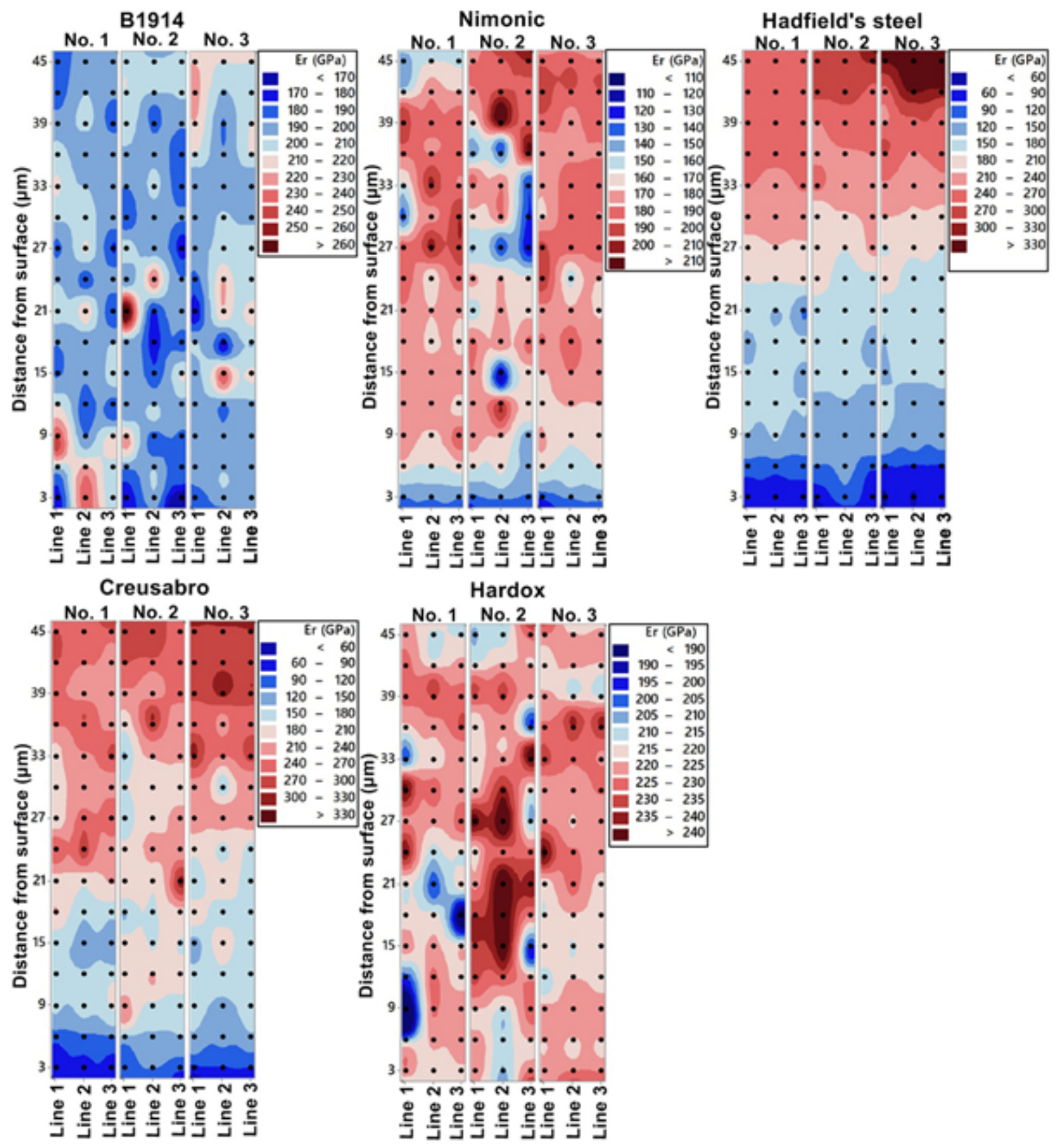

Figure 5

Reduced elastic modulus maps for individual materials and Samples made of them 1, 2 and 3. 

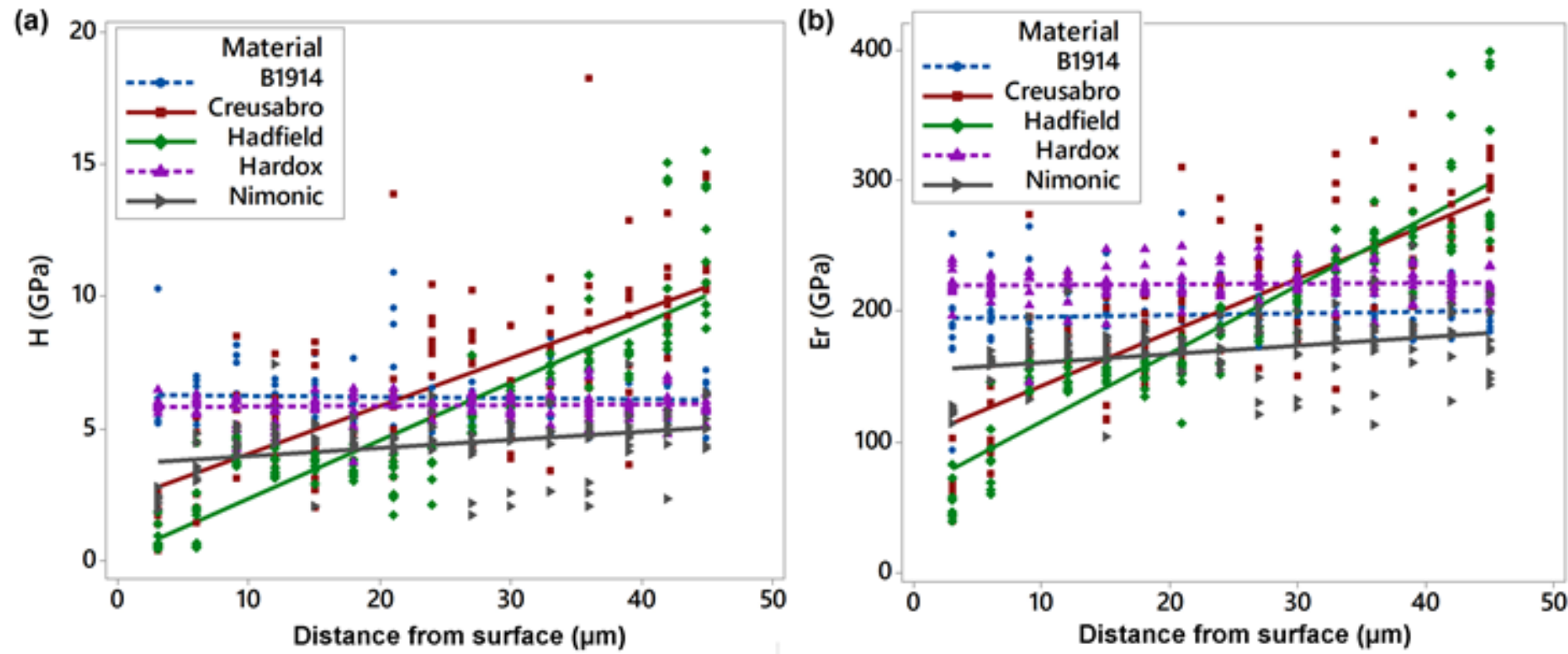

Figure 6

(a) Scatter plot of $\mathrm{H}$ vs Distance from surface (b) Scatter plot of Er vs Distance from the surface.

\section{Supplementary Files}

This is a list of supplementary files associated with this preprint. Click to download.

- Table13.pdf 